\title{
Article
}

\section{Development of Cosmetic Formulations Using Rheological Properties -Generation of New Aqueous Thickeners and Novel Attempt for Quantitative Sensory Evaluation-}

\author{
Ayano NaKamurA*, Atsushi SogABE* ${ }^{*}$ Akiko MACHIDA*, and Isamu Kaneda ${ }^{* *}$ \\ *SHISEIDO RESERCH CENTER \\ 2-2-1 Hayabuchi, Tsuzuki-ku, Yokohama-shi, Kanagawa, 224-8558, Japan \\ ${ }^{* *}$ Department of Food Science and Wellness, College of Agriculture, \\ Food and Environment Science, Rakuno Gakuen University \\ 582 Bunkyodai Midorimachi, Ebetsu, Hokkaido, 069-8501, Japan
}

\begin{abstract}
Cosmetic formulations are composed by various ingredients. In particular, aqueous thickeners play important role in both functional and sensory aspects in formulations. We mention about our attempts to use microgels as intelligent aqueous thickener and to quantify the texture of the cosmetics, by using the rheological properties. Agar microgel dispersion was prepared from agar bulk-gel which was granulated by high-speed mixer (5000 rpm). The inverse microemulsion polymerization system was also studied to create a fine microgel. The thickening effect of the microgel prepared by using the system was higher than that of the agar microgel. The flow characteristic parameters of the microgels were analized by using Herschel-Bulkley equation which is a scaling law model. It was revealed that both the microgels present refresh feeling through power index $n$ in H-B equation. Flow properties of cosmetic lotions, containing various kinds of aqueous thickeners, were studied by creep measurement, and parameters were calculated from their rheological data based on the Nutting equation, which is an empirical equation. There were some correlations among the time dependency parameter $\alpha$ and some sensory evaluation points, assessed by human panels. Simple linear regression analysis revealed that the evaluation scores of slimy feeling, sticky feeling, refresh feeling, and penetrating feeling of the cosmetic lotions were converted to numerical data by the parameter $\alpha$. This quantification method for the texture of cosmetic products will be a useful tool for efficient development of cosmetic formulations.
\end{abstract}

Key Words: Microgel / Herschel-Bulkley equation / Nutting parameter / Texture / Aqueous thickener

\section{レオロジー手法を活用した化粧品基剤開発 一新規水溶性高分子増粘剤の創出と感触の定量化一}

\author{
中村 綾野 ${ }^{*}$, 曽我部 敦 ${ }^{*}$, 町田 明子 *, 金田 勇 ${ }^{* *}$
}

(原稿受理：2013 年 2 月 28 日)

\section{1. 緒言}

化粧品は薬事法において「人の身体を清潔にし, 美化し, 魅力を増し, 容貌を変え, または皮膚もしくは毛髪をすこ やかに保つために身体に塗布, 散布, その他これらに類似 する方法で使用されることが目的とされているもので, 人 体に対する作用が緩和なもの」と定義されている，人々は 化粧行為を通して健常な皮膚を維持するとともに, 高揚感 やリラックス効果など, 心的な満足感を得ることができる. この機能面だけではなく感性的な側面も重要である点にお いて，化粧品は非常に難解で興味深い分野であると捉えら れ，物質の変形と流動に関する学問である「レオロジー」は

* 資生堂リサーチセンター † 224-08558 横浜市都筑区早渕 2-2-1

** 酪農学園大学 農食環境学群 食と健康学類 † 069-8501 江別市文京台緑町 582
化粧品の研究開発にとって非常に重要な役割を担っている.

化粧品は複雑な組成物であり，その構成要素は多岐に渡 る。構成要素はそれぞれの機能を担っているが, 我々はこ の中でも特に「増粘剤」に注目した研究を続けてきた。増 粘剤が化粧品, 特に乳化物処方において果たす役割は, 連 続相を増粘して乳化安定性を高めること, 分散安定性を高 めることなどの機能面が挙げられる。ささらに塗布時の流動 特性を変える, すなわち, 適切な増粘剤を配合することで, 「みずみずしさ」「さっぱりさ」，および「しっとりさ」など の化粧品の使用感触の基本を調整し感性的な側面の演出が 可能であり, 増粘剤のバリエーションは化粧品基剤構築上 非常に重要であると言える。古くからローカストビーンガ ムなどの天然高分子やヒドロキシエチルセルロースなどの 半合成高分子, キサンタンガムなどの微生物産生高分子が 増粘剤として使用されてきた。これらは高分子の絡み合い 
により増粘効果が得られるが, その絡み合いの特性ゆえ,「べ

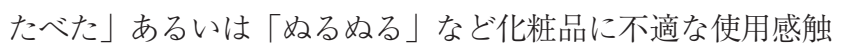
になりやすい，そこで我々は高分子構造に着目し使用感触 について検証を行い, 高分子の物理構造と使用感触に相関 があることを見出した。同一化学構造の高分子であっても, 架橋点を持たない直鎖状の高分子は絡み合いに由来する糸 曳きが見られるが ${ }^{1,2}$ ，部分的に架橋や分岐が導入されると みずみずしく 3,4$)$ ，さらに分子全体を架橋したゲルにするこ とでさっぱりみずみずしい使用感触を呈することが分かっ てきた。また，ミクロゲル分散体はミクロゲル粒子同士の 接触による摩擦で増粘効果を発揮すると考えられ, 増粘効 果の点でもメリットが大きい. 我々はこのミクロゲルを化 粧品の増粘剤として活用する検討を行った。

1つ目として, 寒天を静置状態で冷却ゲル化させた後機械 的に破砕したミクロゲルを, 増粘剤として活用する検討を行っ た ${ }^{5,6)} ミ$ ミロゲル形成条件に関する検討を行い, 得られたミ クロゲル分散液の流動特性を指数則粘度式の Herschel-Bulkley 式を用いて解析し, 増粘機構や使用感触について考察した.7

2つ目として, より高い増粘効果の発揮を目指し, 界面 活性剤が形成する会合体を利用したナノサイズの微小空間 で水膨潤性ポリマーの重合を試みた. ${ }^{8)}$ 水/ポリオキシエチ レン型非イオン性界面活性剤／油の三成分系は, 転相温度 を境に低温で O/W エマルション, 高温でW/O エマルション を形成することが知られており ${ }^{9,10)}$ ，この転相温度付近では 水/油界面張力が極小になり非常に弱い攪拌力でも微細な エマルション相が生成する。この微細なエマルション相に おいてミクロゲルを合成しその流動特性を解析することで, 微細なミクロゲルによる優れた増粘効果, ならびに増粘機 構や使用感触について考察した.11,12,13)

最後に，物理量による使用感触の定量化を試みた。化粧 品の使用感触をコントロールするのは, 試作 · 官能評価の 繰り返しであった。 人による使用感触評価は, 最も現実に 即し感度も高い評価である一方で客観性に劣るという久点 がある，そこで我々は，化粧品の塗布プロセスを反映する と考えられる物性評価, 例えば流動特性や粘弾性特性など から得られる物理量を変数として用い, 官能評価結果を定 量的に表現するアプローチを行ってきた。

化粧品基剤の使用感触評価については，降伏応力值およ

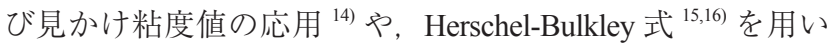
た解析の応用，フロー測定によるヒステリシス特性の応用 ${ }^{17)}$ など様々なアプローチが行われている，本報では，化粧品の 塗布プロセスのうち塗り始めの感触に注目し, クリープ測 定結果を粘弾性体のかたさを評価する経験式である Nutting の式 ${ }^{18,19,20)}$ を用いて解析し, 得られたパラメーターと, 一般 消費者による使用テストから得られる使用感触スコアの相 関について検証した.21)

\section{2. 実験}

\section{1 材料および調製}

\subsection{1 寒天ミクロゲル ${ }^{5,6,7}$}

寒天は低強度寒天 AX-30（伊那食品工業, 伊那市) を精製 せず用いた。寒天を $1.3 ， 1.5$, および $1.7 \mathrm{wt} \%$ の濃度で $90{ }^{\circ} \mathrm{C}$ に加熱したイオン交換水に溶解した後, 室温で 12 時間放置 しバルクゲルを調製した。バルクゲルを T. K. ホモミキサー
(特殊機化工業, 大阪市) を用いて回転数 $5000 \mathrm{rpm}$ で 2 分間 粉砕してミクロゲル分散液を調製した。寒天濃度 $1.3,1.5$, $1.7 \%$ のバルクゲルから調製されたミクロゲル分散液をそれ ぞれMG1.3, MG1.5, MG1.7とした。

2.1.2 逆相マイクロエマルション重合法によるミクロゲル ${ }^{11,12,13)}$ 非イオン性界面活性剤としてポリオキシエチレンオレイ ルエーテル $\mathrm{C}_{18} \mathrm{E}_{3}$ （商品名エマレックス 503）拈よび $\mathrm{C}_{18} \mathrm{E}_{6}$ （エマレックス 506）（日本エマルション，東京）を精製せず 用いた。モノマーは2-アクリルアミド-2-メチルプロパン スルホン酸 (AMPS, Aldrich, St. Louis, MO, USA), ジ メチルアクリルアミド (DMAA, 興人, 東京), 架橋剤とし てN-N’メチレンビスアクリルアミド（MBA， Aldrich）を 精製せず用いた。重合開始剤は過硫酸アンモニウム（APS, Aldrich）を精製せず用いた，その他の試薬, 水酸化ナトリウム, ヘキサン, 2-プロパノール, およびエタノールは和光純薬（大 阪）から購入して精製せず用いた。実験に使用した水はす ベてイオン交換水を用いた。

重合条件を決めるため, 相図の作成を行った。水相とし てモノマー水溶液を用い, モノマー濃度は $20 \mathrm{wt} \%$, モノマー 組成は DMAA : AMPS $=80: 20$ (mol 比) とした。油相はへキ サンとした。水相：界面活性剤：油相比は 47.7 : 4.6:47.7（重 量比）とした。配合する界面活性剤はエマレックス 503 と 506 を混合し，計算上のエチレンオキサイド付加 $\mathrm{mol}$ 数が 4 〜 6 になるように調整して配合した。 それぞれ $\mathrm{C}_{18} \mathrm{E}_{4}, \mathrm{C}_{18} \mathrm{E}_{5}$, $\mathrm{C}_{18} \mathrm{E}_{6}$ と記す。相図作成用のサンプルは架橋剤および重合開 始剂を配合せず，少量の重合禁止剤を加えて温度変化によ る相状態を観察して相図を作成した。

作成した相図を用い，各種ミクロゲルを合成した。モノ マー水溶液に架橋剤としてMBA を全モノマー量に対して $0.1 \mathrm{~mol} \%$ 添加し重合した。重合は重合開始剤を除くすべて 原料を還流管，窒素ガス導入管を備えた四つロフラスコに 入れ，窒素ガスで系内の酸素を十分パージした後，オイル バスで重合温度である $65{ }^{\circ} \mathrm{C}$ まで加熱した。重合開始剤（全 モノマー量に対して $0.1 \mathrm{~mol} \%$ ）を添加して 4 時間重合反応 を進行させた。重合反応終了後, 重合液に過剩量のアセト ンを加えミクロゲルを沈殿回収した. さらにこの沈殿を2プロパノールで再膨潤させた後さらにアセトンを加えて再 沈殿させた. この工程を 3 回繰り返した後, 得られた沈殿 を減圧下で乾燥することで白色の粉末として回収した，回 収率はいずれのサンプルもほぼ $100 \%$ であった。なお，界 面活性剤の組成は $\mathrm{C}_{18} \mathrm{E}_{4}, \mathrm{C}_{18} \mathrm{E}_{5}, \mathrm{C}_{18} \mathrm{E}_{6}$ に調整し重合を行った （サンプルコード:DA04-01，DA05-01，DA06-01）。

\section{2 流動挙動の解析}

流動特性は全て, ストレス制御型回転式レオメーター （MCR300; Paar Physica, Stuttgart, Germany）を用いて測定した。

\section{2 .1 寒天ミクロゲル ${ }^{5,6,7)}$}

定常流粘度測定はずり速度 $0.03 \sim 30 \mathrm{~s}^{-1}$ の範囲で測定した。 測定治具は直径 $50 \mathrm{~mm}, 2^{\circ}$ のコーンを用い, $25{ }^{\circ} \mathrm{C}$ で測定を 行った。

ミクロゲルの流動挙動を定量的に検討するため, ずり応 力一ずり速度曲線を Herschel-Bulkley 式にフィッティングし て降伏応力, 擬塑性粘度および粘性指数を算出した。 


$$
\sigma=\sigma_{0}+K\left[\frac{d \gamma}{d t}\right]^{n}
$$

ここで，。はずり応力， $\sigma_{0}$ は見かけの降伏応力， $\mathrm{K}$ は見 かけの粘性係数, $\mathrm{d} \gamma / \mathrm{dt}$ はずり速度を示す。また, $\mathrm{n}$ は H-B 指数である. フィッティングはデータ解析ソフト (Universal software US 200, Paar Physica) を用いて行った.

\subsection{2 逆相マイクロエマルション重合によるミクロゲル ${ }^{11,12,13)}$}

見かけ粘度はずり速度 $10 \mathrm{~s}^{-1}$ で 1 分間測定し, 1 分後の值 とした，見かけの降伏応力はずり応力変化に対するずり速 度変化の測定を行い, データ解析ソフト (Universal software US 200, Paar Physica) を用いた解析により, ずり応力変化の 変曲点を見かけの降伏応力 $\sigma_{\text {app }}$ として算出した。 測定治具は 直径 $50 \mathrm{~mm}, 2^{\circ}$ のコーンを用い, $25^{\circ} \mathrm{C}$ で測定を行った。

\subsubsection{Nutting パラメーターを応用した感触定量化 ${ }^{21)}$}

各モデル美容液について，30 秒間の最大ひずみが $5 \%$ 未 満になる範囲で印加応力を $0.5 \mathrm{~Pa}$ 毎に 5 水準設定し, クリー プ測定を行った。測定治具は直径 $50 \mathrm{~mm}, 2^{\circ}$ のコーンを用い, $25{ }^{\circ} \mathrm{C}$ で測定を行った。

得られた一定応力下でのひずみ成長曲線（ $\mathrm{t}=1-10 \mathrm{~s} ）$ を Nutting の式 (2) $)^{6}$ を用いて解析した。

$$
\varphi=\sigma^{\beta} \gamma^{-1} t^{\alpha}
$$

ここで $\varphi$ はサンプルの総合的なかたさ, $\sigma$ は応力, $\gamma$ はひずみ, $\mathrm{t}$ は時間を示す。 $\varphi$ は粘弾性的なかたさを, $\alpha$ は変形の時間 依存性を, $\beta$ は変形の応力依存性を表すパラメーターである. 具体的には, クリープ測定におけるそれぞれの印加応力に ついて, $\mathrm{t}=1 \mathrm{~s}$ から $\mathrm{t}=10 \mathrm{~s}$ までのひずみ成長曲線の, 両対 数プロットの傾きを最小二乗法で決定し $\alpha$ を求めた. 次い で印加応力と $\mathrm{t}=10 \mathrm{~s}$ におけるひずみの両対数プロットの傾 きを最小二乗法で決定し $\beta$ を，切片より $\varphi$ を決定した。

\section{3. 結果および考察}

\section{1 寒天ミクロゲルのレオロジー特性}

Figure 1 に各濃度で調製した寒天ミクロゲルのずり応力一 ずり速度曲線，およびこれを Herschel-Bulkley 式 (1)を用い てフィッティングした結果を示す?)

実験データはいずれも Herschel-Bulkley 式によくフィッ ティングした。 Table I に寒天ミクロゲル，およびキサンタン ガム, カルボキシビニルポリマーなど化粧品で用いられる 増粘剤，さらには比較として果物ピューレやトマトケチャッ プなどの食品の各パラメーターを示す ${ }^{7,22,23)} \mathrm{n}$ 值が大きいほ どさらさら流れるようになり，また， $0.3 \sim \mathrm{n} \sim 0.5$ の範囲 のものが, 感覚的に「さっぱり」したテクスチャーである と考えられた。寒天ミクロゲルの $\mathrm{n}$ 值は 0.31 であり, 非常 にさっぱりした感触であると言える。

Figure 2 に寒天ミクロゲルの体積分率 $\phi_{\mathrm{gel}}$ と, 応力 - ず り速度曲線を Herschel-Bulkley 式により解析し算出した見 かけの降伏応力 $\sigma_{0}$ の関係を示す?) 寒天濃度 $1.5 \mathrm{wt} \%$ および

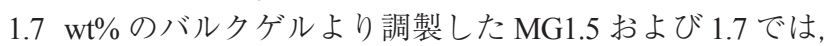
$\phi_{\mathrm{gel}}$ が 0.8 と 0.7 の間を境に $\sigma_{0}$ が急激に低下した。一方, 寒 天濃度 $1.3 \mathrm{wt} \%$ のバルクゲルより調製した MG1.3では, 体

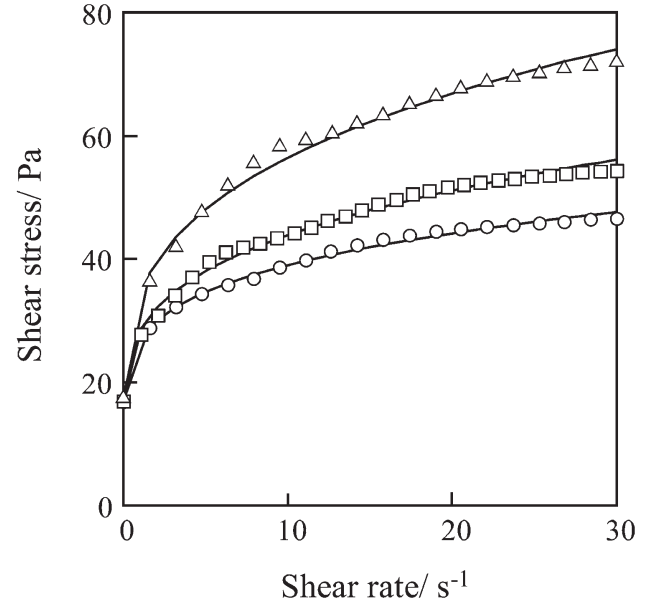

Fig. 1. Flow curves for agar microgel dispersions. The circles represent MG1. 3, prepared from 1. $3 \mathrm{wt} \%$ agar bulk-gel, ; the squares, MG1. 5, prepared from 1. $5 \mathrm{wt} \%$ agar bulk-gel, ; the triangles, MG1. 7, prepared from $1.7 \mathrm{wt} \%$ agar bulk-gel. The curves indicate calculated values from Herschel-Bulkley equation by using experimental data. All measurements were done at $25^{\circ} \mathrm{C}$.

(From Nihon Reoroji Gakkaishi, 30(2), 89(2002), with permission from the Reoroji Gakkaishi)

Table I. Herschel-Bulkley parameters of various aqueous dispersions.

\begin{tabular}{cccc}
\hline Sample & $\sigma_{0} / \mathrm{Pa}$ & $\mathrm{K} / \mathrm{Pa} \cdot \mathrm{s}$ & $\mathrm{n}$ \\
\hline \hline MG1.5 & 13.5 & 14.9 & 0.309 \\
Xanthan gum 1\% aquaous solution & $\sim 0$ & 32.0 & 0.087 \\
Carboxy vinyl polymer & & & \\
0.5\%aquaous solution ${ }^{\mathrm{a})}$ & $\sim 0$ & 15.0 & 0.292 \\
Apple pulpe & & & \\
Tomato juice & - & 65.0 & 0.084 \\
Tomato ketchup & - & 6.1 & 0.43 \\
Milk & 32.0 & 18.7 & 0.27 \\
\hline
\end{tabular}

a) The aqueous solution neutrized by potassium hydroxide to $\mathrm{pH} 6.5$

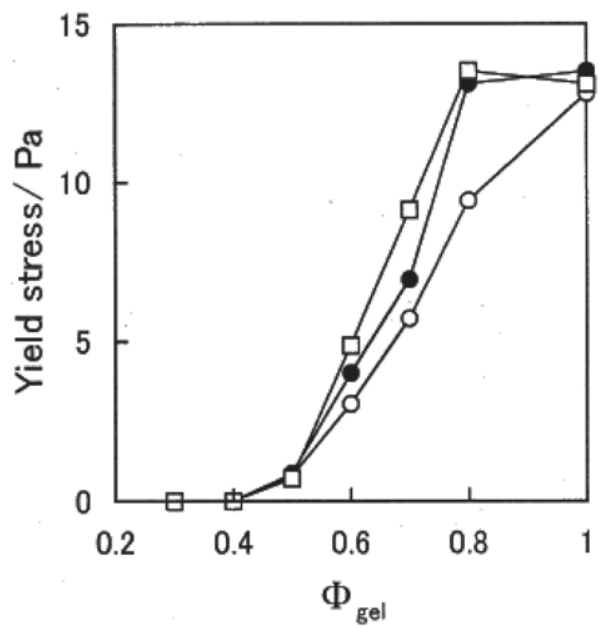

Fig. 2. Dependence of apparent yield stress on microgel volume fraction for agar microgel dispersion. The open circles represent MG1. 3, prepared from $1.3 \mathrm{wt} \%$ agar bulk-gel, ; the closed circles, MG1. 5, prepared from $1.5 \mathrm{wt} \%$ agar bulk-gel, ; the squares, MG1. 7, prepared from 1. $7 \mathrm{wt} \%$ agar bulk-gel. $\phi$ gel indicates the volume fraction of microgel particles in the dispersion. The values of apparent yield stress were calculated from Herschel-Bulkley equation.

(From Nihon Reoroji Gakkaishi, 30(2), 89(2002), with permission from the Reoroji Gakkaishi) 
積分率の低下に従い連続的に $\sigma_{0}$ が低下した。さらに，いず れの濃度で調製した寒天ミクロゲルも， $\phi_{\mathrm{gel}}=0.4$ 以下では見 かけの降伏応力が消失した。この結果から, 見かけの降伏 応力はゲル粒子の充填状態に依存すると考えられる。また, 寒天濃度により $\sigma_{0}$ の変化挙動に相違があることから，ミク ロゲル粒子自体の硬さもこれに影響を与えると考えられる。

\section{2 逆相マイクロエマルション重合によるミクロゲルの レオロジー特性}

Figure 3 に界面活性剤としてポリオキシエチレンオレイル エーテル $\left(\mathrm{C}_{16} \mathrm{E}_{3}\right.$ : エマレックス 503, $\mathrm{C}_{16} \mathrm{E}_{6}$ : エマレックス 506), 水相として DMAA と AMPS の $20 \mathrm{wt} \%$ 水溶液, 油相 としてn-ヘキサンを用いた三成分系の相図を示す ${ }^{11}$. 縦軸 は温度, 横軸は界面活性剤のエチレンオキサイド付加モル 数を示し, 実線は転相曲線を示す。転相温度付近における 複雑な相状態変化を観察した結果, 転相温度から $3 \sim 5{ }^{\circ} \mathrm{C}$ 上 の範囲で外観上透明な逆ミセル溶解相と思われる相が観察 された.エチレンオキサイドの付加モル数を $5 \mathrm{~mol}$ 程度にす ることで, 重合温度として設定した $65^{\circ} \mathrm{C}$ 付近に転相温度が 出現する。

Table II に, W/O 二相領域 $\left(\mathrm{C}_{18} \mathrm{E}_{4}\right)$, 転相温度近傍の逆相 エマルション領域 $\left(\mathrm{C}_{18} \mathrm{E}_{5}\right)$ および $\mathrm{O} / \mathrm{W}$ 二相領域 $\left(\mathrm{C}_{18} \mathrm{E}_{6}\right)$ の 三点において重合したDA04-1，DA05-01，およびDA06-01 の $0.5 \%$ 水分散液の見かけ粘度を示す ${ }^{11)}$ 転相温度近傍で重 合が進行したDA05-01 は極めて高い増粘効果を示した。重

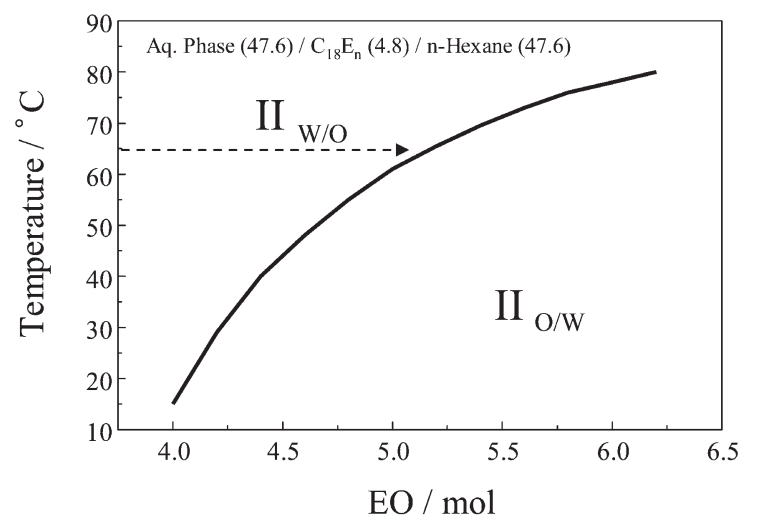

Fig. 3. The phase diagram of the inverse microemulsion polymerization system. The line in the figure shows the phase inversion temperature. The doted line shows the polymerization temperature in the study.

(From J. Soc. Cosmet. Chem. Japan, 39(4), 282(2005), with permission from the J. Soc. Cosmet. Chem. Japan)

Table II. The results of polymerization using various surfactants.

\begin{tabular}{cccc}
\hline Sample & SAA $^{\mathrm{a})}$ & $\begin{array}{c}\text { The outside of } \\
\text { polymerization system }\end{array}$ & Viscosity $^{\mathrm{b})} / \mathrm{mPa} \mathrm{s}$ \\
\hline \hline DA04-01 & $\mathrm{C}_{18} \mathrm{E}_{4}$ & W/O opaque & 3000 \\
DA05-01 & $\mathrm{C}_{18} \mathrm{E}_{5}$ & W/O transparent & 17000 \\
DA06-01 & $\mathrm{C}_{18} \mathrm{E}_{6}$ & O/W opaqure & - \\
\hline
\end{tabular}

a) A nonionic surfactant used in this study

b) The values of the viscosity for the samples were measured using B type viscometer

(From J. Soc. Cosmet. Chem. Japan, 39(4), 282(2005), with permission from the J. Soc. Cosmet. Chem. Japan)
合中の外観も透明〜半透明であり, マイクロエマルション 内で重合が進行し,微細なミクロゲルが生成したと考えられ た。一方，DA04-01 は重合中の外観が白濁しており，粒子 径の大きな W/O二層エマルション内で重合が進行したため, 増粘効果が低いと予想された。 DA06-01については O/Wの 連続相である水相で重合が進行したため, 系全体がゲル化 してしまった。以上の結果から，転相温度近傍の極めて微 細なエマルションという制限された空間内でミクロゲルを 重合することで, 増粘効果の高いミクロゲルを合成可能で あることが確認できた。

Figure 4 に得られたミクロゲル (DA05-01) 分散液の濃度と 見かけ粘度，および見かけの降伏応力の関係を示す。ミクロ ゲル分散液濃度と見かけ粘度の関係においては, 粘度上昇の 緩やかな領域 (Region1), 急激に粘度が上がる領域 (Region2), さらには再び粘度上昇が緩やかになる領域 (Region3)の3つ の領域が観察された。通常の高分子水溶液の挙動では, 高濃 度領域において増粘傾向が緩やかになる現象は見られない ことから，DA05-01 がミクロゲル粒子の充填によって粘度が 出ており，ある濃度以上では高分子の絡み合いとは異なる挙 動を取ることを示唆している. 見かけの降伏応力は Region2 の中間付近から発現することが分かった。 そこで，ミクロゲ ル粒子の充填状態の直接観察を行った. Figure 5 に見かけ降 伏応力が発生する $0.18 \mathrm{wt} \%$ ミクロゲル水分散液の凍結割断 面のレプリカ膜を, 透過型電子顕微鏡 (H-7000, 日立製作所) で観察した結果（FF-TEM 像）を示す。ミクロゲル粒子が充 填し, さらにゲル自体が変形することで密なパッキング状態 を形成していることが分かる。まずミクロゲル同士が接触 しあう濃度から急激に見かけ濃度が上昇し，さらにそのパッ キングが密になることで見かけ降伏応力が発生すると考え られる。

DA05-01 ミクロゲル分散液の流動特性を先述の HerschelBulkley 式を用いて解析した結果, $\mathrm{n}$ 值は 0.3 付近であり, 寒

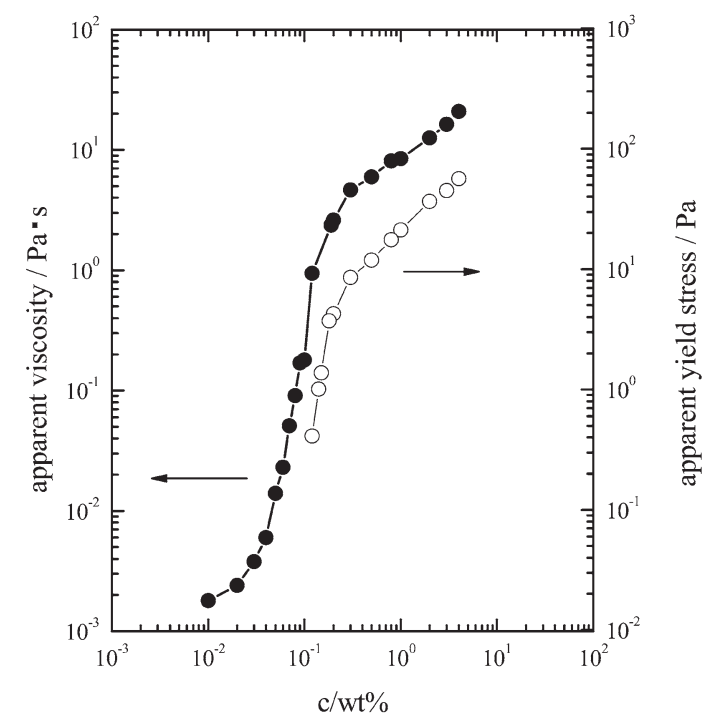

Fig. 4. The apparent viscosity and the apparent yield stress of microgel suspensions as a function of concentration. Closed circles and open circles represent the apparent viscosity and the apparent yield stress, respectively. 
天ミクロゲルと同様に「さっぱり」した使用感触であること が示唆された，また，寒天ミクロゲルと比較して粒子径が 小さくかつ均一であり，より少ない高分子配合量で増粘効 果が発揮された。このような特性を持つミクロゲルは, 増粘, 乳化・分散安定化などの機能に加え, 感触においても優れ た特徵を示す増粘剂として, 化粧品への幅広い応用が期待 される。

\subsection{Nutting パラメーターを応用した感触定量化}

Herschael-Bulkley 式を用いた使用感触の客観的評価は, 「さっぱりさ」を評価する優れた手法であるが, 同様に「さっ ぱり」した使用感触を示す寒天ミクロゲルと逆相エマルショ ン重合法によるミクロゲルなどの素材同士を比較するのは 困難であった，そこでさらに詳細に感触の定量化を検討す べく, 食品業界に打いてチーズの成熟状態を客観的に評価 する手法として検討されていた Nutting の式 ${ }^{18,19,20)}$ を用いた

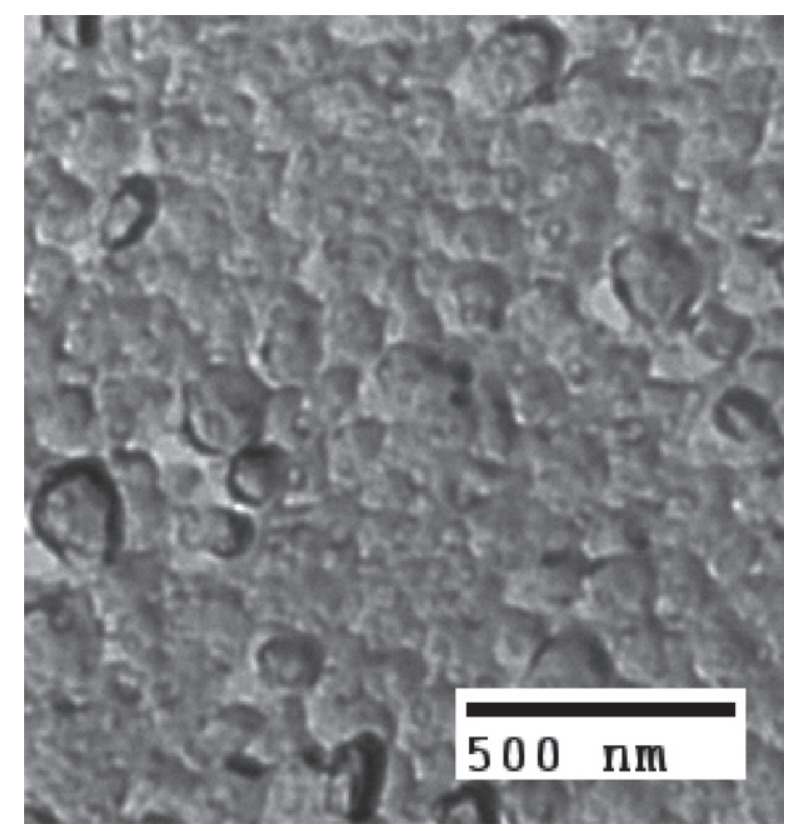

Fig. 5. The FF-TEM image of microgel suspensions. The concentration of the microgel was prepared to $0.18 \mathrm{wt} \%$ in ion exchanged water.
検討を行った

水溶性増粘剂としてカルボキシビニルポリマー（3V Sigma), DMAA/AMPS クロスポリマー（東邦化学，2.2で記 述した逆相マイクロエマルション重合法によるミクロゲル, DA05-01), 寒天ミクロゲル（2.1で記述した寒天バルクゲル を破砕したミクロゲル），サクシノグリカン（ローデイア日 華)，ポリアクリルアミド（Seppic，精製によりポリマーの みを回収して使用）を選択して Table III に示すモデル美容液 処方を調製した。

Table IV ${ }^{21}$ に各モデル美容液の Nutting の式による解析結果 を示す。いずれのサンプルも見かけ粘度は同程度であるが, $\alpha$ 值拧よび $\varphi$ 值が増粘剂種によって大きく異なることが分 かった.

各種水溶液増粘剂を配合した美容液 6 品について，20 代 および 30 代の一般女性各 50 名（さっぱり好き，しっとり好 き各 25 名）を対象とした使用テストを実施した. 1 人につ き 3 品の美容液をそれぞれ 3 日間, 自宅で朝晚洗顔後の肌 に手で使用し, 美容液の使用感触として重要な 33 評価項目 に対し，5段階評価のアンケートを行った。

モデル美容液の使用感触に関するアンケート結果と, Nutting パラメーターの相関を検証した結果， $\alpha$ について複 数の項目で高い相関が得られた。一方， $\beta$ 抢よび $\phi$ と使用感 触項目に相関は得られなかった。 $\alpha$ 值との相関係数が 0.8 以 上の官能評価項目は 4 項目抽出された.

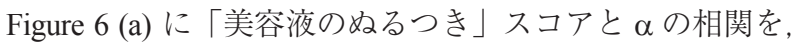
線形単回帰分析により解析した結果を示す. ${ }^{21}$ なお， 本評価 項目は逆転項目として評価した。両者は非常に高い相関を 示し $\left(\mathrm{R}^{2}=0.91\right)$, レオメーターにより測定可能な物理パラメー ターである $\alpha$ を用いて, 「美容液の好つき」の評価スコア を『6.6 × $\alpha-4.2(\mathrm{p}=0.0029$ ：回帰倸数は有意 $)$ の式で定 量化することができた。ここでスコアは $\alpha$ に対して正の相 関であることから，変形の時間依存性を表すパラメーター

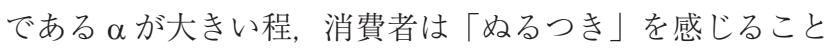
が分かった。

Figure 6 (b) に「肌のさっぱりさ」スコアと $\alpha$ の相関を, 線形単回帰分析により解析した結果を示す. ${ }^{21} \Gamma$ 肌のさっぱり さ」スコアと $\alpha$ は高い相関を示し $\left(\mathrm{R}^{2}=0.80\right)$,「肌のさっぱ りさ」の評価スコアは『 $-3.9 \times \alpha+3.8(\mathrm{p}=0.00167:$ 回帰係 数は有意)』の式で定量化することができた。ここでスコア

Table III. Formulae of model essence.

\begin{tabular}{|c|c|c|c|c|c|c|}
\hline \multirow{2}{*}{ Ingredient } & \multicolumn{6}{|c|}{ wt $\%$} \\
\hline & $\mathrm{U}$ & $\mathrm{S}$ & $\mathrm{P}$ & $\mathrm{Q}$ & $\mathrm{T}$ & $\mathrm{R}$ \\
\hline Ethanol & 3 & $\leftarrow \leftarrow$ & $\leftarrow$ & $\leftarrow \leftarrow$ & $\leftarrow \leftarrow$ & $\leftarrow$ \\
\hline Glycerin & 6 & $\leftarrow$ & $\leftarrow$ & $\leftarrow$ & $\leftarrow$ & $\leftarrow$ \\
\hline Buthylen glycol & 5 & $\leftarrow$ & $\leftarrow$ & $\leftarrow$ & $\leftarrow$ & $\leftarrow$ \\
\hline (Polyoxyethylen/Polyoxypropylene) dimethyl ether & 1 & $\leftarrow$ & $\leftarrow$ & $\leftarrow$ & $\leftarrow$ & $\leftarrow$ \\
\hline Carboxyvinylpolymer & 0.2 & - & - & - & - & - \\
\hline Dimethylacrylamide/Sodium Acryloyldimethyltaurate Crosspolymer & - & 0.7 & - & - & - & - \\
\hline Polyacrylamide & - & - & 0.7 & - & - & - \\
\hline Agar & - & - & - & 1.2 & 0.96 & - \\
\hline Succinoglycan & - & - & - & - & 0.24 & 1.2 \\
\hline Acyrlates/C10-30 Alkyl Acrylate Crosspolymer & 0.03 & $\leftarrow$ & $\leftarrow$ & $\leftarrow$ & $\leftarrow$ & $\leftarrow$ \\
\hline Potassium Hydroxide & 0.76 & 0.1 & $\leftarrow$ & $\leftarrow$ & $\leftarrow$ & $\leftarrow$ \\
\hline Dimethylpolysiloxane & 2 & $\leftarrow$ & $\leftarrow$ & $\leftarrow$ & $\leftarrow$ & $\leftarrow$ \\
\hline Trisodium EDTA & 0.02 & $\leftarrow$ & $\leftarrow$ & $\leftarrow$ & $\leftarrow$ & $\leftarrow$ \\
\hline Phenoxyethanol & 0.35 & $\leftarrow$ & $\leftarrow$ & $\leftarrow$ & $\leftarrow$ & $\leftarrow$ \\
\hline Water & to 100 & $\leftarrow$ & $\leftarrow$ & $\leftarrow$ & $\leftarrow$ & $\leftarrow$ \\
\hline
\end{tabular}

(From Nihon Reoroji Gakkaishi, 37(5), 247(2009), with permission from the Reoroji Gakkaishi) 
は $\alpha$ に対して，「ぬるつき」と逆の負の相関であり， $\alpha$ が小 さい程消費者は「さっぱりさ」を感じることが分かった。ま

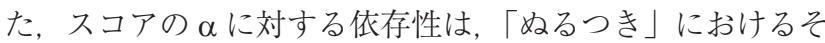
れより小さいことが分かり， $\alpha$ は「さっぱりさ」より「ぬる つき」を精度良く定量化可能と言える。

Table IV. Nutting Parameters of model essences.

\begin{tabular}{ccccc}
\hline Code & $\begin{array}{c}\text { Apparent viscosity } \\
/ \mathrm{mPa} \cdot \mathrm{s}^{\text {a }}\end{array}$ & $\alpha$ & $\beta$ & $\varphi$ \\
\hline \hline $\mathrm{U}$ & 15,400 & 0.054 & 0.99 & 1.17 \\
$\mathrm{~S}$ & 13,000 & 0.104 & 1.21 & 1.77 \\
$\mathrm{P}$ & 12,500 & 0.126 & 1.10 & 1.37 \\
$\mathrm{Q}$ & 14,000 & 0.064 & 1.95 & 7.79 \\
$\mathrm{~T}$ & 11,500 & 0.146 & 1.29 & 1.42 \\
$\mathrm{R}$ & 12,000 & 0.243 & 0.948 & 0.506 \\
\hline
\end{tabular}

a) The value of the viscosity for the samples was measured using VH type viscometer. (From Nihon Reoroji Gakkaishi, 37(5), 247(2009), with permission from the Reoroji Gakkaishi)
Figure 6 (c) に「美容液の肌へのしみこみ」スコアと $\alpha$ の 相関を, 線形単回帰分析により解析した結果を示す ${ }^{21)}$.「美 容液の肌へのしみこみ」スコアと $\alpha$ は非常に高い相関を示 し $\left(\mathrm{R}^{2}=0.86\right), 「$ 肌へのしみこみ」の評価スコアを『-7.1 $\times \alpha$ + 3.7 ( $\mathrm{p}=0.0077$ : 回帰係数は有意)』の式で定量化すること ができた。ここでスコアは $\alpha$ に対し「さっぱりさ」と同様に 負の相関であり， $\alpha$ が小さい程消費者は「肌へのしみこみ」 を感じることが分かった。 また，スコアの $\alpha$ に対する依存

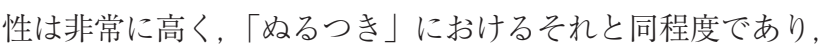

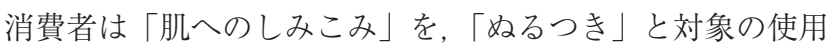
感触として捕らえている可能性がある.

Figure $6(\mathrm{~d})$ に「肌のべたつき」スコアと $\alpha$ の相関を，線 形単回帰分析により解析した結果を示す ${ }^{21)}$.「肌のべたつき」 スコアと $\alpha$ は高い相関を示し $\left(\mathrm{R}^{2}=0.83\right), 「$ 肌のべたつき」 の評価スコアを『4.3 × $\alpha+1.9(\mathrm{p}=0.011$ : 回帰係数は有意 $) 』$ の式で定量化することができた。ここでスコアは $\alpha$ に対し て正の相関であり， $\alpha$ が大きい程消費者は「べたつき」を感

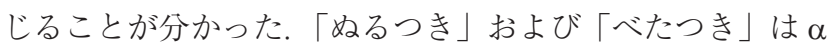

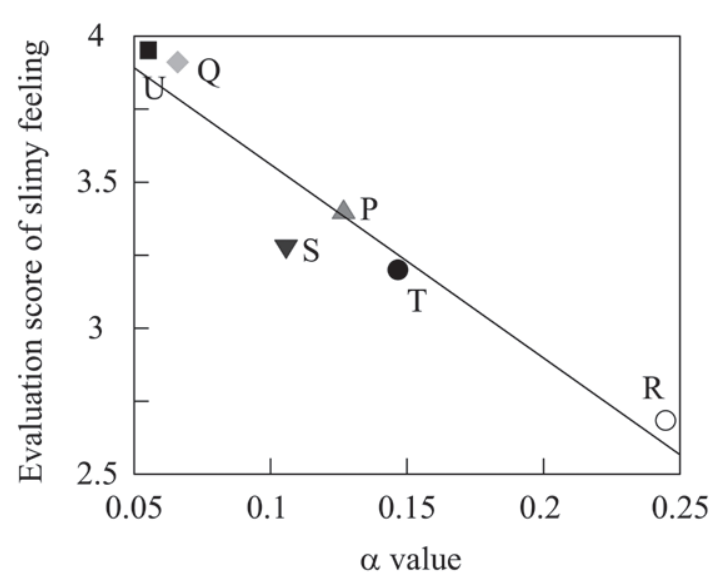

(a) Slimy feeling

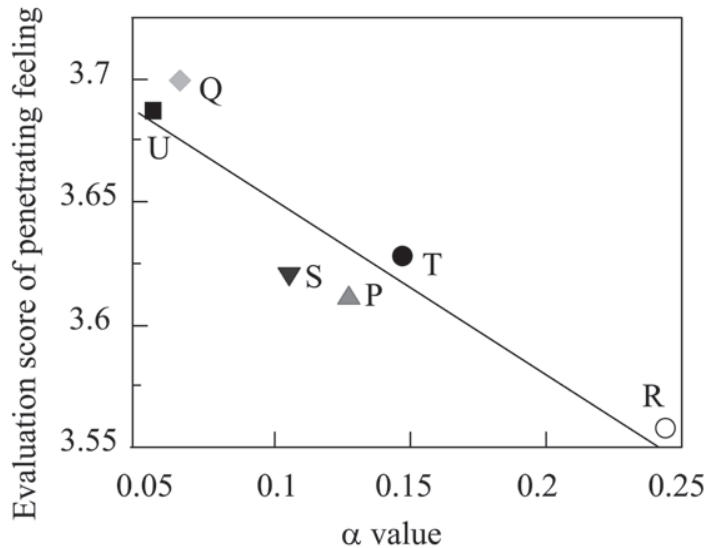

(c) Penetrating feeling

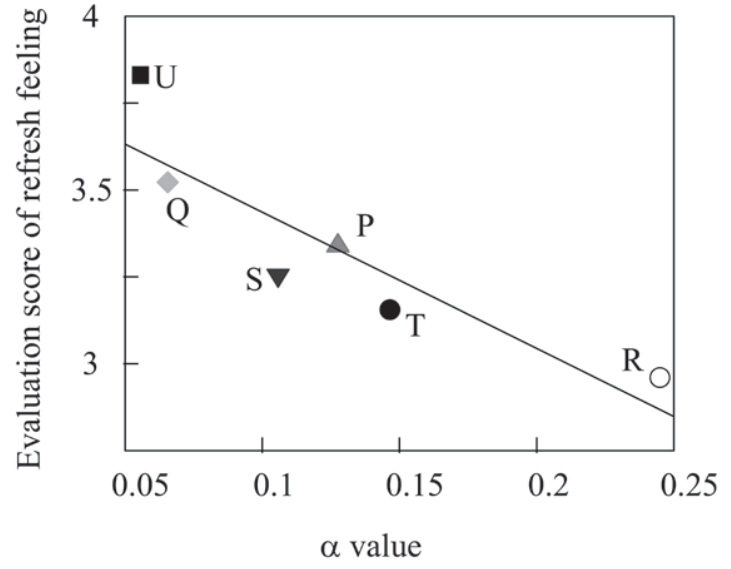

(b) Refresh feeling

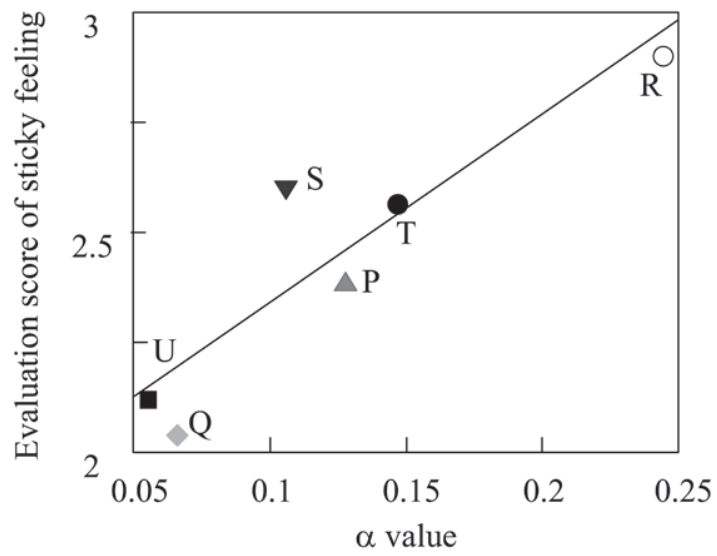

(d) Sticky feeling

Fig. 6. Correlation between Nutting Parameter $\alpha$ and sensory evaluation score through simple linear regression analysis. (From Nihon Reoroji Gakkaishi, 37(5), 247(2009), with permission from the Reoroji Gakkaishi) 


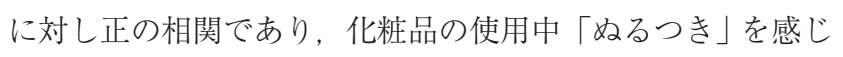
る場合, 使用後に「べたつき」を感じる可能性が高いと考え られる，以上述べたように官能評価スコアを，レオメーター で測定可能な物理的パラメーターを用いて定量的に記述す ることに成功した。

これまで担当者が官能評価によって主観的に行っていた 順位付けを, 客観的な物性值を用いて定量化し数值で順位 付けできるため, 処方開発における指針として応用が可能 であり，開発の効率化に有効な手段であると言える。

\section{4. 結 論}

化粧品基剤中において水溶性増粘剤が果たす役割につい て, 増粘効果, 乳化·分散安定化という機能的な側面に加え, 「みずみずしさ」「さっぱりさ」，および「しっとりさ」など 化粧品の使用感触を調整する感性的な側面に注目し, 我々 のグループが行ってきた水溶性増粘剤の開発および使用感 触定量化の試みについて述べた。

ミクロゲルの調製・合成方法について検討を行い，ミク ロゲル分散液のような降伏応力を持つ流体は, 乳化・分散安 定化という機能面に優れる増粘剤になり得ることを示した. また，流動特性を実験粘度式である Herschel-Bulkley 式によ

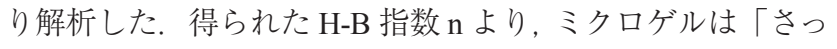
ぱり」した使用感触であることを定量的に示した．

また，使用感触の異なる水溶性増粘剤を配合したモデル 美容液を用いてクリープ測定を行い, Nuttingの式により解 析した，得られるパラメーターと, 官能評価による使用感触 の評価スコアとの相関を線形単回帰分析により解析し, 変 形の時間依存性を示すパラメーターである $\alpha$ と, 美容液の

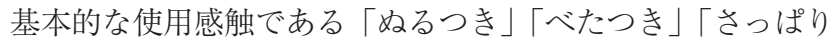
さ」, および美容液の嗜好を左右する使用感触である「肌へ のしみこみ」の各評価スコアについて, 高い相関が得られ, 使用感触を物性值により定量的に評価することに成功した。

増粘剤のレオロジー特性を十分に検討し活用したこれら の研究は, 今後の基剤開発にとって非常に有用な知見であ ると言える。

\section{REFERENCES}

1) Nakagawa T, Bull Chem Soc Japan, 25(2), 88 (1952).

2) Nakagawa T, Bull Chem Soc Japan, 25(2), 93 (1952).

3) Ketz Jr. RJ, Prud'homme RK, Graessley WW, Rheol Acta, 27, 531 (1988).

4) Nae HN, Reichert WW, Rheol Acta, 31, 351 (1992).

5) Miyazawa K, Kaneda I, Yanaki T, Japanese Patent 3531734.

6) Miyazawa K, Kaneda I, Yanaki T, Japanese Patent 3531735.

7) Kaneda I, Yanaki T, Nihon Reoroji Gakkaishi, 30(2), 89 (2002).

8) Kaneda I, Sogabe A, Nakajima H, J Colloid Interface Sci, 275, 450 (2004).

9) Kunieda H, Shinoda K, J Dispers Sci Technol, 3, 233 (1982).

10) Shinoda K, Prog Colloid Polym Sci, 68, 1 (1983).

11) Kaneda I, Sogabe A, Nakajima H, J Soc Cosmet Chem Japan, 39(4), 282 (2005).

12) Kaneda I, Sogabe A, Colloids Surf A, 270-271, 163 (2005).

13) Kaneda I, Nihon Reoroji Gakkaishi, 34(2), 77 (2006).

14) Wittern KP, Brummer R, Study in Surface and Catalysis, 123, 1031 (2001).

15) Herschel WH, Bulkley R, Kolloid-Z, 39, 291 (1962).

16) Scott Blair GW, "Elementary Rheology", Academic Press, London, p.53 (1969).

17) Ban S, Fragrance Journal, 34(5), 63 (2006).

18) Nutting PG, J Franklin Inst, 191, 679 (1921).

19) Scott Blair GW, Coppen FMV, J Soc Chem Ind Chemistry \& Industry, 60, 447 (1941).

20) Scott Blair GW, J Texture Stud, 1, 431 (1970).

21) Nakamura A, Sogabe A, Machida A, Kaneda I, Nihon Reoroji Gakkaishi, 37 (5), 247 (2009).

22) Holdsworth D, J Texture Stud, 2, 393 (1971).

23) Barbosa C, Peleg M, J Texture Stud, 14, 213 (1983). 